\title{
Exploring How Rhetorical Organization Contributes to the Readability of Essays
}

\begin{abstract}
John R. Baker
Ton Duc Thang University

Correspondence regarding this article should be addressed to Dr. John R. Baker, Ton Duc Thang University, 19 Nguyen Huu Tho St, Tan Phong Ward, Dist. 7, Ho Chi Minh City, Vietnam.

E-mail: drjohnrbaker@tdtu.edu.vn

The facilitative benefits of genre-specific reading have often been cited as a truism in the field of writing education. In line with this, writing center self-access libraries typically provide a selection of composition texts, including rhetorics (anthologies of model paragraphs and essays). Readability formulae (e.g., the Lexile Readability Formula) are often used to determine whether these texts will be a good fit for potential readers, and although the Lexile Formula reliably and validly assesses two features (i.e., semantic and syntactic), it does not consider other contributing features during the text selection process (e.g., rhetorical organization). To address this, this sequential, mixed-methods study explored the effects of rhetorical organization on undergraduate English language learners' perceptions of difficulty when reading exemplars (i.e., essays) excerpted from rhetorics. The results indicated that rhetorical organization influences readability both as (a) a primary (i.e., an isolated feature) and (b) a conjoined feature (i.e., comprising two or more associated entities where the second impacts the first). The article also provides a suggestion for writing education professionals and the publishing industry: Readability formulae should be administered in a hybrid fashion, where additional features such as rhetorical organization are subjectively considered when assessing the difficulty of exemplars.
\end{abstract}

Keywords: lexile, readability, rhetorical organization, text selection, rhetorics, model essays, second language writing, writing center administration

\section{Introduction}

The facilitative benefits of genre-specific reading have often been cited as a truism in the field of writing education (Hyland, 2007), especially as genre-specific reading provides heuristics that result in better writing (Johns, 2003), with correlations of .50 to .70 (Grabe \& Zhang, 2016). Therefore, writing center self-access libraries typically provide a selection of composition texts, including rhetorics (Baker, 2020), "rhetorically organized anthologies of paragraphs and essays which explicate rhetorical forms, present sample texts exemplifying major rhetorical patterns, and offer procedures to show student writers how to reproduce such genre in their own writing" (Ferris \& Hedgcock, 2005, p. 130). Accepting that rhetorical knowledge supports good writing (Liao \& Chen, 2009), that collections of model essays are facilitative (Abe, 2008; Qi \& Lapkin, 2001), and that providing rhetorics is a standard writing center self-access resource library practice (Chromik, 2002), it is imperative to consider whether such texts will be a good fit for potential users' reading levels (Mesmer, 2008), "the study of which ... has come to be called readability" (Gilliand, 1972, p. 12).

The field of readability has received a considerable amount of attention in the last century (Dubay, 2007a); consequently, there are many definitions of readability (Gilliand, 1972; Harrison, 1980; Kintsch \& Miller, 1981; Kintsch \& Vipond, 1979; Klare, 1963; Schirmer \& Lockman, 2001). The consensus is, as Dale and Chall (1949) aptly pointed out, that readability is "the sum total (including all the interactions) of all those elements within a given piece of printed material that affect the success a group of readers have with it" (p. 23). One metaphorical definition, however, stands out as especially illuminating (Chall et al., 1996), as it compares readability to an iceberg: "Beneath the surface, there are various sources of difficulty. The more difficult the passage, the greater the ice beneath" (p. 6). This definition is elucidating because it highlights that readability, like an iceberg, is not 
a solid, homogeneously opaque entity. Rather, it is a heterogeneous mix of features that make up the complex phenomenon known as reading (Goodman, 1967; Koda, 2005).

Explorations of readability span back as far as $900 \mathrm{AD}$ (Lorge, 1944), receiving greater attention in the early $20^{\text {th }}$ century (Pearson et al., 2016). Historical accounts show that these early investigations were primarily quantitative (measuring semantic features, syntactic features, or a mix of the two ${ }^{1}$ ) (Gunning, 2003; Klare, 1984; Mesmer, 2008), thus providing the theoretical underpinning of the first readability formula (i.e., Lively \& Pressey, 1923), which Klare (1963) has termed a predictive device that provides quantitative, objective estimates of difficulty. Since then, formulae have traditionally utilized these two features, which have been repeatedly shown to be reliable indicators of readability (Dubay, 2007b). Soon after the introduction of the first formula, however, Ojemann (1932), Gray and Leary (1935), and recently others (Armbruster, 2016; Chall \& Dale, 1995; Fry, 2002; Gunning, 2003; Kintsch \& Vipond, 1979; Lexile, 2010; Meyer, 2003) have recognized that additional features need to be taken into account in the course of comprehensive text/reader combination assessments, a position that continues to be held today (Baker, 2019).

Accepting that a comprehensive assessment process requires moving beyond a single-step formula and adopting a two-stage approach (using a formula and subjective criteria together) reduces the risk of providing seemingly appropriate texts but "ones readers cannot read due to format, language, structure, or content" (Weaver, 2000, p. 33), the field has been undergoing a paradigm shift toward a hybrid approach (Baker, 2019) in which a readability formula is first utilized and then other features are explored qualitatively (Fry, 2002).

Looking back to Pressey and Lively (1923), hundreds of formulae have been published; however, only a few remain in popular use. One of the most frequently used is the Lexile Readability Formula (Lexile, 2010), and while this formula reliably assesses two features (i.e., semantic and syntactic), there has been a growing call in the literature for users to utilize a more holistic hybrid approach (Gunning, 2003; Lexile, 2010). Gunning (2003), for instance, illustrated this concern, suggesting that "although teachers might use Lexiles ..., they need to go beyond the numbers ... [and] complement the objective data yielded by the formula with subjective judgment" (pp. 182-186).Unfortunately, the in-depth study of additional features is an understudied area. In order to address this gap, this sequential mixed-methods study investigated what effects (benefits and difficulties) one feature, rhetorical organization, has on undergraduate English language learners' (ELLs) perceptions of difficulty when they read exemplars (i.e., essays) excerpted from rhetorics.

\section{Literature Review}

Discussions of how rhetorical organization influences readability often begin with a delineation of text types, which are typically considered to be in one of two major categories based on rhetorical organization: narrative or expository. The structure of expository texts is then further classified. Drawing on the literature on rhetoric (i.e., Aristotle) and linguistics (Grimes, 1975), Meyer (1975) identified five basic ways to organize expository discourse: (a) causation, (b) collection, (c) comparison, (d) description, and (e) problem/solution. These are not the only ways texts have been categorized. In fact, although these terms are frequently used, empirical taxonomy investigations have added to and adapted them, and they often vary among researchers.

\section{Taxonomy Studies}

Drawing on the themes of text complexity and student awareness, a limited amount of empirical work has discussed which text types native English speakers (NESs) and ELLs find the most difficult. Pointing to a lack of published taxonomies, Bereiter (1978), using more detailed text-type descriptors (e.g., narrative-fictional and factual, abstract topical exposition), conducted an early study with NES text complexity and proposed a taxonomy of text types from easiest to most difficult based on the complexity of each text type's organization, listing the narrative type as easiest and expository types as more difficult.

\footnotetext{
"Readability measures use similar factors to predict comprehension difficulty--some aspect of word difficulty measured either as word familiarity, word frequency, abstract versus concrete words, or word length--number of syllables, number of letters, or affixes, etc.--and some measure of sentence complexity, measured either by average sentence length, or by complex versus simple sentences" (Chall, 1996, p. 24).
} 
Other empirical works using variations of text-type terms closer to those in use today and employed in this study (e.g., illustration, process, description, narrative, cause/effect, comparison/contrast, and argumentation/ persuasion) have reported taxonomies regarding how difficult NES and ELL readers find different text types. However, these studies provide an inconclusive picture. Although several are replication studies, the results are inconsistent. Further confusion arises as the foci (text types) and methodology vary from one study to another. Finally, the texts and the participants' reading levels are insufficiently described.

\section{Table 1}

Taxonomies of Text Types

\begin{tabular}{|c|c|c|c|}
\hline & Easy & 4 & Difficult \\
\hline Carrell (1984a) & \multicolumn{3}{|c|}{ comparison-causation - problem/solution - collection of descriptions $s^{a}$} \\
\hline Meyer \& Freedle (1984) & \multicolumn{3}{|c|}{ comparison - problem/solution - causation - collection of descriptions } \\
\hline Fooh (1989) & \multicolumn{3}{|c|}{ problem/solution - collection of descriptions } \\
\hline Goh (1990) & \multicolumn{3}{|c|}{ comparison. ${ }^{*}, *$, } \\
\hline Freedle \& Kostin (1991) & \multicolumn{3}{|c|}{ comparative - argumentative } \\
\hline Talbot, et al., (1991) & \multicolumn{3}{|c|}{ causation - collection of descriptions - comparison - problem/solution } \\
\hline Freedle \& Kostin (1993) & \multicolumn{3}{|c|}{ list/describe - problem/solution } \\
\hline Sharp (2002) & \multicolumn{3}{|c|}{ description - problem/solution - listing - cause/effect } \\
\hline Yali \& Jiliang (2007) & \multicolumn{3}{|c|}{ narrative - cause } \\
\hline Zhang (2008) & \multicolumn{3}{|c|}{ description - problem/solution - comparison/contrast } \\
\hline Lei (2010) & \multicolumn{3}{|c|}{ collection - problem/solution } \\
\hline
\end{tabular}

Note.

a. Only two structures were examined.

b. Text types followed Carrell (1984a), but ranking varied across proficiency levels.

Accepting that the results of the aforementioned taxonomy studies are inconsistent, that is which text types are more difficult than others has not been consistently determined, a moderate amount of research has explored what factors contribute to such incongruity.

\section{Sources of Rhetorical Organization Difficulty}

Expanding on Meyer's (1975) work and the taxonomy studies that followed, a limited number of historical studies have been undertaken with NESs and ELLs to determine which factors contribute to rhetorical organizational difficulty. Two major sources of difficulty have been cited. The first is the relative complexity of each text type (rhetorical organization). Narratives, for example, have been found to be less complex than expository texts, and certain types of expository texts have been found to be less complex than others. A second source of difficulty cited is how familiar readers are with the text types, which Carrell (1987) referred to as formal schemata: "knowledge relative to the formal, rhetorical organizational structures of different types of texts" (p. 481). Spiro and Taylor (1980) elaborated on both of these themes, pointing out that conducting research to determine which text types are more difficult or easier for students is difficult because what constitutes a text type is not standardly defined. They also highlighted that complexity can occur because texttype characteristics are not found exclusively in one type of text or the other; that is, while a text may be defined by its major rhetorical structure, it may include other text types. A narrative text type, for example, "can possess many of the typical characteristics of exposition and vice versa" (p. 1). With regard to awareness, Spiro and Taylor (1980) further elucidated that it is difficult to hold students' formal schemata of organizational structures constant.

A similar warning regarding the complexity of text structure and students' awareness was given about conducting research with ELLs. Selinker et al. (1976), in an early work, emphasized and demonstrated that the definition of text type may actually be a rhetorical mixture that contains elements of cause and effect, classification, comparison, and description. They also identified that the main difficulty lies in whether the reader can recognize these forms. Specifically, they explained: 
The nonnative reader often lacks those abilities which will allow him to recognize the existence of certain types of implicit presuppositional rhetorical information ... and gain access to the total informational content of that discourse. (p. 282)

Calfee and Curley (1984) presented a similar observation, reporting that ELLs are often unable to comprehend the complete meaning of text types "even when they understand all of the words in each sentence and all of the sentences that make up the discourse" (p. 282). Flick and Anderson (1980) reached similar conclusions about student awareness, but they noted that the lack of rhetorical awareness is not unique to ELLs.

A third area of cited difficulty is how vocabulary (the number of unfamiliar, abstract, figurative, or technical words in a text) contributes to readers' perceptions of difficulty. Davis (1944), in one of the few studies in this area (rhetorical organization's relationship with other factors), identified several hundred factors that influence reading comprehension, many of which overlapped. Specifically, he argued that readers' ability to follow the organization of a passage corelated with their ability to understand the vocabulary therein. More recently, as mentioned above, Freedle and Kostin $(1991,1993)$ conducted a series of studies to determine which variables contribute to reading passage difficulty in standardized tests (SAT, TOEFL). They reported that vocabulary contributed significantly to text difficulty, although the foci of the cline of difficulty differed in each study. Specifically, they argued that vocabulary was related to students' ability to make inferences related to texts that violated traditional text structure.

The fourth conjoined area is titles. Bock (1980), in an exploration of the effects of meaningful titles on NES undergraduates' identification of text types, found that "titles provide the starting point for setting up text structures" (p. 308). Schwartz and Flammer (1981) similarly found that titles have an effect on NES undergraduates' understanding of text structure.

\section{Materials and Methods}

This sequential mixed-methods study explored the effects (benefits and difficulties) rhetorical organization has on undergraduate ELLs' perceptions of difficulty when they read essay exemplars excerpted from rhetorics ${ }^{2}$.

\section{Setting}

The study was conducted at a university in northern Taiwan that maintains a writing center which serves the university's 9,000 students. The writing center receives a variety of visitors. These include (a) students from writing courses offered for English majors (two years of requisite composition courses, Freshman and Sophomore Composition, and a requisite business writing course), (b) students from the English department and 15 other disciplines whose courses include writing components, and (c) students seeking help with other writing needs.

\section{Overall Design}

This study explored one research question: What effects (benefits and difficulties) doesrhetorical organization have on undergraduate English language learners' (ELLs) perceptions of difficulty when they read exemplars (i.e., essays) excerpted from rhetorics? To explore this research question, a sequential mixed-methods adaption of Creswell's (2013) design was utilized (Figure 1).

Following the sequential mixed-methods design, the researcher, who was both the writing center director and course instructor for one of the sections of Sophomore Composition, administered two steps and their relevant stages: (a) Identifying participants and texts (exemplars) and (b) Exploring the benefits and difficulties of rhetorical organization for students who read exemplars from rhetorics.

\footnotetext{
2 This article reports the results of a larger unpublished sequential, mixed-methods study (i.e., a doctoral dissertation) that explored the effects of textual features on postsecondary ELLs' perceptions of difficulty when reading exemplars from rhetorics. The methodology presented in this paper was adapted from the larger study.
} 
Figure 1

Sequential mixed-methods research design

\begin{tabular}{|c|l|}
\hline \multicolumn{1}{|c|}{\begin{tabular}{|l|} 
Step 1 \\
A quantitative comparison of students' \\
reading levels (using the Scholastic Reading \\
Inventory) and texts readability levels \\
(using the Lexile Readability Formula) to \\
identify participants and texts.
\end{tabular}} \\
$\qquad$\begin{tabular}{|l|l|} 
A qualitative exploration of the benefits and \\
difficulties rhetorical organization poses to \\
students who read exemplars from rhetorics.
\end{tabular} \\
\hline A cline-questionnaire procedure & $\begin{array}{c}\text { Qualitative } \\
\text { A further exploration of the results of the cline-questionnaire } \\
\text { procedure via semi-structured retrospective interviews }\end{array}$ \\
\hline
\end{tabular}

\section{Identifying Participants and Texts (Exemplars)}

To identify participants and texts for this study, three stages were undertaken: (a) an examination of the target sample's reading levels, (b) an examination of the rhetorics' (i.e., the exemplars therein) Lexile levels, and (c) a comparison of the two.

To identify potential participants, the Scholastic Reading Inventory (SRI) was administered to a purposive sample $(\mathrm{N}=91)$ of students registered in sections of Sophomore Composition. This cluster group was selected as (a) the members of this group comprised the majority of writing center visitors and (b) they had (as a result of attending the English department's composition course) been introduced to the text-type terms used in the questionnaire (e.g., rhetorical organization, process, description, narrative, comparison, and argumentation/ persuasion). However no attempts were made to control for awareness.

To identify the exemplars for study, rhetorics available on the local market $(\mathrm{N}=12)$ and the exemplars therein $(n=893)$, were measured with a computerized version of the Lexile Analyzer. To determine which exemplars are accessible to the reading levels of the selected participants, the participants' reading levels and exemplars' Lexile levels were compared.

In accordance with qualitative theory, the participants were purposively selected to help the researcher explore the phenomenon. Considering sample sizes for homogeneous purposive samples (3-10, Creswell, 2013; 6-8, Kuzel, 1992; $10+3$, Francis, et al., 2010; $15 \pm 10$; Kvale, 1996), a cluster sample of informants $(n=14)$ was purposively identified according to their SRI scores, the top $15 \%$ of the students enrolled in sections of Sophomore Composition (828-928L), thus allowing them to compare a wide range of exemplars in order to aid the researcher in holistically exploring the research question (Merriam, 1991).

The identified participants were queried by e-mail for consent to a follow-up post-course interview. Twelve informants assented and were provided with pseudonyms, females ( $n=7$; mean age 20.14 years), and males $(n=$ 5 ; mean age 20.8 years). Eleven reported to the test site and 10 successfully completed the procedures, thus providing useful data. The sample composition was indicated by the students' Lexile measures rather than any purposeful intent of the sampling procedure (e.g., age, ethnicity, gender).

Five exemplars (range 610-1010L) (Table 2) were purposively selected to be below, within, and slightly above the informants' Lexile range. This number of exemplars $(n=5)$ was chosen in order to provide sufficient rhetorical diversity for the informants to engage in thoughtful comparisons but modest enough so that the cline could be performed and articulated within a reasonable period of time (via the questionnaire and interview), such that usable data could be collected but informant fatigue could be prevented. 
Table 2

Exemplars

\begin{tabular}{|c|c|c|}
\hline Titles & Lexile & Type \\
\hline $\begin{array}{l}\text { a. Traig, J. A. (2008). Guide to proper hand-washing technique. In M. L. Conlin (Ed.). } \\
\text { Patterns plus: A short prose reader with argumentation (pp. 176-178). Houghton Mifflin. }\end{array}$ & $610 \mathrm{~L}$ & Process \\
\hline $\begin{array}{l}\text { b. Hughes, L. Salvation. (2007). In S. V. Buscemi, \& C. Smith (Eds.) } 75 \text { readings plus (pp. 10- } \\
\text { 14). McGraw-Hill. }\end{array}$ & $740 \mathrm{~L}$ & Narrative \\
\hline $\begin{array}{l}\text { c. McDonald, C. P. A. (2003). A view from the bridge. In T. Cooley (Ed.). The Norton sampler: } \\
\text { Short essays for composition (pp. 37-41). Norton \& Company. }\end{array}$ & $810 \mathrm{~L}$ & Description \\
\hline $\begin{array}{l}\text { d. Harris, S. (2001). Freedom and security. In G. Levin (Ed.). Prose models (pp. 389-392). } \\
\text { Wadsworth. }\end{array}$ & $910 \mathrm{~L}$ & Argumentation \\
\hline $\begin{array}{l}\text { e. Dalfonos, D. (2003). Grammy rewards. In T. Cooley (Ed.). The Norton sampler: Short } \\
\text { essays for composition (pp. 206-208). Norton \& Company. }\end{array}$ & 1010L & Contrast \\
\hline
\end{tabular}

\section{Description of the Exemplars}

According to Table 2, the "A Guide to Proper Hand-washing Technique" essay is rated as the easiest of the five (i.e., 610L). The rhetoric's editor describes the essay's organization as a process essay, one that outlines a "method of doing a task or a job, usually in orderly steps, to achieve a desired result" (p. 163); in this case, describing how one is to wash one's hands. The "Salvation" essay is rated as the second least difficult (i.e., $740 \mathrm{~L}$ ), described as a narrative that offers an autobiographical account of the author's childhood experience at a church revival meeting. The "A View from the Bridge" essay is rated as the third most difficult (i.e., 810L), described as a descriptive essay, a "mode of writing that appeals most directly to the senses by showing or telling us what something looks like, or how it sounds, smells, feels, or tastes" (p. 21); in this case a jogger's encounter with a visually impaired young fisherman. The editor notes that the essay, as is common in descriptive essays, also contains elements of narration. The "Freedom and Security" essay is rated as the second most difficult (910L), and is described as an argumentative/persuasion essay, one that presents an argument, guiding the reader through "the process of inference of reasoning from a general truth to another general truth or a particular instance" (p. 386). The topic of the essay is that we can disagree with ideas while respecting the people who hold them. "Grammy Rewards," rated as the most difficult of the five essays (1010L), is described as a contrast essay that uses a point-by-point structure to contrast two grandmothers on the basis of how they interact with their granddaughter.

\section{Exploring the Benefits and Difficulties of Rhetorical Organization for Students Who Read Exemplars from Rhetorics}

Following the identification of the participants and the texts, the effects of rhetorical organization were explored via an untimed two-stage process: (a) a quantitative cline-questionnaire procedure and (b) qualitative semi-structured retrospective interviews.

\section{The Quantitative Cline-Questionnaire Procedure}

The quantitative cline-questionnaire procedure had two phases. These are discussed in the following sections.

The Cline Phase. In the cline phase, the participants read the essays $(n=5)$ and constructed a cline (an arrangement of the exemplars from easiest to most difficult). The exemplars were arranged in random order and given to the informants in a plain brown envelope. Ranking criteria were withheld to facilitate the sort of decision-making processes that readers normally undertake when making such judgments (Chall et al., 1996), thus allowing the participants to reflect on what contributed to their rankings (perceptions of difficulty) during the next phase, the questionnaire phase.

The Questionnaire Phase. Following the completion of the clines, a five-point Likert-scale questionnaire was administered to encourage informants to reflect on why they ordered the essays in the sequence they did and explain this in a way that would provide insight into what factors other than those measured by the Lexile Readability Formula (i.e., rhetorical organization) contributed to their perceptions of difficulty. The questionnaire addressed a variety of features related to comprehension (e.g., background knowledge, sentence 
length, titles, vocabulary, vocabulary in context). The question regarding rhetorical organization is listed in Table 3.

Table 3

Excerpt from the questionnaire

Logical Rhetorical Organization: How the ideas were arranged in each text to help them flow logically from one to another influenced my decision about how to arrange the texts in the way that I did.

1. Strongly Agree

2. Agree

3. Neither Agree nor Disagree

4. Disagree

5. Strongly Disagree

Note. The participants, as a result of attending the university's composition course, were familiar with the term logical rhetorical organization, understanding it to refer to terms used in this study: process, description, narrative, comparison, and argumentation/ persuasion.

To avoid language ambiguities, the questionnaire was translated from English and administered in the students' L1 (i.e., Mandarin). The translation was verified by a second translator and pre-tested with participants not included in the sample $(n=2)$.

\section{Qualitative Semi-structured Retrospective Interviews}

The data from the questionnaire were triangulated with semi-structured retrospective interviews following Creswell's (2013) protocol. Enquiries commenced with structured items from the questionnaire (e.g., background knowledge, rhetorical organization, sentence length, titles, vocabulary, vocabulary in context) and were elaborated on through semi-structured prompts, which later became open-ended (Nunan, 1996). This was done to provide greater breadth and scope regarding the data provided by thequantitative cline and questionnaire.

The researcher conducted the interviews, a bilingual research assistant assisted with language difficulties, and an observational protocol (audio and video taping) was followed. The interviews continued until data saturation was reached (mean 32.5 minutes; range 19.3-57.4 minutes; variation was dependent on the degree of information offered and translation required). Audio recordings were transcribed and member checked, the data were coded using emergent category analysis (Erlandson et al., 1993), and a second-level group debate procedure was undertaken to "add strength and fertility to the entire analysis" (p. 128).

\section{Results}

This sequential mixed-methods study explored the effects (benefits and difficulties) rhetorical organization has on undergraduate ELLs' perceptions of difficulty when they read essay exemplars (i.e., essays) excerpted from rhetorics. To explore this, two steps were undertaken. The first identified the texts $(N=5)$ and participants $(N=10)$. The second explored the research question: What effects (benefits and difficulties) does rhetorical organization have on undergraduate English language learners' (ELLs) perceptions of difficulty when they read exemplars (i.e., essays) excerpted from rhetorics?

Overall, the results suggest that rhetorical organization influences students' perceptions of readability both as (a) a primary (i.e., an isolated feature) and (b) a conjoined feature (i.e., comprising two or more associated entities where the second impacts the first).These results are subsequently elaborated further in two areas: (a) the results of the cline-questionnaire procedure and (b) the results of the qualitative semi-structured retrospective interviews and its subsections.

\section{Results of the Cline-Questionnaire Procedure}

The results of the cline procedure are shown in Table 4. The essays, labeled a-e, are arranged according to the informants' rankings from easiest to difficult. 
Table 4

The results of the informants' cline ordering

\begin{tabular}{lccccccccccc}
\hline & Annie & Ben & Dan & Eve & Harold & Jacob & Kala & Linda & Marsha & Nelson \\
\hline Easiest & a & a & a & a & a & a & a & & a & a & a \\
& d & d & b & c & d & e & e & e & e & d \\
& b & b & e & e & e & d & d & d & d & c \\
Difficult & c & c & c & b & b & b & b & c & c & e & c \\
\hline
\end{tabular}

Note:

a_Process, b_Narrative, c_Description, d_Argumentation, e_Contrast

The data were analyzed using SPSS 21, specifically the Friedman test. The results (mean rank table) (Table 5) demonstrated that the process essay had a low average difficulty $(m=1.0)$, while the descriptive essay had the highest average difficulty $(m=4.0)$. Considering the results below, the process essay $(m=1.0)$ was found to be the easiest, followed by argumentation $(m=3.0)$, contrast $(m=3.10)$, narrative $(m=3.90)$, and description $(m=$ 4.0).

Table 5

Descriptive statistics

\begin{tabular}{lccccc}
\hline & N & Mean & Std. Deviation & Minimum & Maximum \\
\hline a_Process & 10 & 1.0000 & .00000 & 1.00 & 1.00 \\
b_Narrative & 10 & 3.9000 & .99443 & 2.00 & 5.00 \\
c_Description & 10 & 4.0000 & .94281 & 2.00 & 5.00 \\
d_Argumentation & 10 & 3.0000 & 1.15470 & 2.00 & 5.00 \\
e_Contrast & 10 & 3.1000 & 1.19722 & 2.00 & 5.00 \\
\hline
\end{tabular}

The results, as shown in Table 6, reveal that there was a significant difference in the ranking of each essay $\left(\chi^{2}\right.$ $(4)=23.28, p<.001)$, thus demonstrating that the informants made definitive choices in their rankings.

\section{Table 6}

Friedman test statistics

\begin{tabular}{ll}
\hline \multicolumn{2}{c}{ Test Statistics } \\
\hline $\mathrm{N}$ & 10 \\
Chi-Square & 23.280 \\
Df & 4 \\
Asymp. Sig. & .000 \\
\hline
\end{tabular}

Examining the predictive Lexile measures alongside the students' rankings (Table 7), the results illustrate that the student rankings (a, d, e, b, c) contradict the Lexile results (a, b, c, d, e). 
Table 7

Comparison of Lexile and participants' rankings

\begin{tabular}{lll}
\hline \multicolumn{1}{c}{ Lexile Cline } & \multicolumn{1}{c}{ Student Cline } & Mean \\
\hline a_Process (610L) & a_Process (610L) & 1.00 \\
b_Narrative (740L) & d_Argumentation (910L) & 3.00 \\
c_Description (810L) & e_Contrast (1010L) & 3.10 \\
d_Argumentation (910L) & b_Narrative (740L) & 3.90 \\
e_Contrast (1010L) & c_Description (810L) & 4.00 \\
\hline
\end{tabular}

\section{Results of the Questionnaire}

After the informants finished their clines, they completed the closed-response questionnaire. The results of the questionnaire indicated that the informants found rhetorical organization to be one of 15 primary (isolated) features that contributed to the readability of the exemplars in the rhetorics. Interestingly, rhetorical organization approached the level of effect held by the first feature measured by the Lexile Readability Formula (i.e., semantic). Nine of the ten informants (90\%) cited vocabulary and vocabulary in context as influential, and $80 \%$ reported similar results for rhetorical organization. Moreover, rhetorical organization had a larger impact than the second feature employed by readability formulae (i.e., syntactic and sentence length). Eighty percent of the participants reported rhetorical organization to be influential as a primary feature, whereas only $50 \%$ reported similar results for sentence length. This unexpected result is likely due to the fact that the overall impact of sentence length as a mediating factor is not considered only as a primary feature, as its influence is also compounded by its conjoined properties (e.g., grammar, punctuation, and vocabulary) (Dubay, 2007b).

\section{Results of the Qualitative Semi-Structured Retrospective Interviews}

After the informants completed the questionnaire, they engaged in semi-structured retrospective interviews. An analysis of the informants' qualitative responses further demonstrated that the informants as a group perceived rhetorical organization to be a primary feature (i.e., an isolated feature). The results also demonstrated that the informants perceived logical organization to be a conjoined feature (i.e., consisting of two or more associated entities where the second impacts the first). These results are discussed in the following sections.

\section{Primary Feature}

Logical organizationwas again, as was done in the questionnaire, cited as a primary feature by eight (80\%) of the informants (Annie, Ben, Eve, Harold, Jacob, Linda, Marsha, Nelson).Examining the informants' responses, their perceptions appeared to stem from an entangled mix of two causes: (a) the informants' awareness of (or lack of awareness of) the type of rhetorical organization exemplified in the essays and therhetorical organization of the essays themselves. Eve illustrated an example of both by demonstrating a strong awareness of rhetorical structure by naming the rhetorical organization of each essay, explaining that she felt each organization style was easier than the last.Eve's comments are related to previous taxonomy literature which reported that the logical organization of a text can impact readers' perceptions of difficulty (Bereiter, 1978 as cited in Calfee \& Curley, 1984; Carrell, 1984a; Fooh, 1989; Freedle \& Kostin 1991, 1993; Goh, 1990; Lei, 2010; Meyer \& Freedle, 1984; Lei, 2010; Sharp, 2002; Talbot, Ng, \& Allan, 1991; Yali \& Jiliang, 2007; Zhang, 2008).A second informant, Ben, further demonstrated how a lack of awareness can play a part.Discussing the contrast organization of the "Grammy Rewards" essay and the essay's place in his cline, he pointed out that he felt that the essay's point-by-point structure was hard to understand because "the two grandmothers show up in the same paragraph."Ben's report supports literature which explains that a readers' "knowledge relative to the formal, rhetorical organizational structures of different types of texts" (Carrell 1987, p. 481) contributes to perceptions of difficulty. 


\section{Conjoined Features}

The results of the interviews showed that rhetorical organization is conjoined with other features (Table 8). Forty percent of the respondents (Annie, Ben, Dan, Kala) explained that they perceived rhetorical organization to be directionally influential as a conjoined feature, conjoined with three features: (a) vocabulary, (b) background knowledge, and (c) titles. Rhetorical organization was also found to influence one other primary feature, vocabulary in context.

\section{Table 8}

Features the informants reported to be conjoined with other features

\begin{tabular}{llc}
\hline Conjoined Features & Influential Features & Influence \\
\hline Rhetorical Organization & Vocabulary & - \\
Rhetorical Organization & Background Knowledge & + \\
Rhetorical Organization & Title & + \\
Vocabulary in Context & Rhetorical Organization & + \\
\hline
\end{tabular}

Note.+ denotes a positive influence; - denotes a negative influence.

Rhetorical Organization and Its Relationship with Vocabulary and Vocabulary in Context. Rhetorical organization was found to have a negative relationship with vocabulary and a positive relationship with vocabulary in context. Two (20\%) of the informants (Annie, Kala) explained that they felt the amount of unfamiliar vocabulary in an essay diminished their ability to understand its logical organization. Kala, for example, referring to the "A View from the Bridge" essay, explained that she felt that the vocabulary in the essay was so difficult that she could not understand the essay's organization. Kala's report is related to Hirsch and Nation's (1992) work, which showed that students need to have a minimum command of vocabulary to access a text. Her report is also related to Carrell's (1983b) work, which has shown that when students are presented with texts beyond their ability, the students may remain linguistically tied to the text, unable to access other features that would normally help them process the material.One informant, Dan, also reported that he felt vocabulary in context was influenced by logical organization. He explained that he had trouble fully understanding the concepts freedom and security when he first came across them in the title of the "Freedom and Security" essay, but that he was later able to understand them because of the essay's logical contrast organization. Dan's report is associated with Dubin and Olshtain's (1993) work, which showed that comparison or contrast clues can assist readers' ability to make inferences. It also supports others' reports that inference clues at the sentence and paragraph level are helpful (Bengeleil \& Paribakht, 2004; Paribakht \& Wesche, 1999).

Rhetorical Organization and Its Relationship with Background Knowledge and Titles. For the remaining two features (i.e., background knowledge and titles), one response was offered for each. For the first, background knowledge, Ben, explained that he felt that his background knowledge about hand washing (i.e., the topic of the "A Guide to Proper Hand-washing Technique" essay) helped him identify its rhetorical organization (process), which in turn helped him anticipate and follow the text. For the second feature, titles, Dan explained why he considered the title of the essay, "A Guide to Proper Hand-Washing Technique," to be assistive. He reported that the essay's title helped him understand the essay's logical organization because he could anticipate that the essay would be reporting a procedure. Dan's report is in accordance with Bock's (1980) work, which explained that titles can help informants set up ideas about forthcoming logical organization. Ben's report is loosely related to others who have reported a link between background knowledge and comprehension (Carrell, 1983a; Dochy, et al., 1999), but no direct links between rhetorical organization and background knowledge were found during the literature review for this study.

\section{Discussion and Conclusion}

Accepting that readability is a worthy area of inquiry (Mesmer, 2008), even though the readability of essays found in rhetorics is underexplored (Baker, 2019), this study investigated the effects of rhetorical organization on ELL apprenticing writers' perceptions of text difficulty when reading exemplars excerpted from rhetorics. 
As mentioned in the previous section, the results suggest that rhetorical organization influences students' perceptions of readability both as (a) a primary (i.e., an isolated feature) and (b) a conjoined feature (i.e., comprising two or more associated entities where the second impacts the first). These results were borne out by two procedures and the resulting data:(a) results of the cline-questionnaire procedure and (b) results of the qualitative semi-structured retrospective interviews and its subsections. These results are further elaborated on in this section to illustrate how these procedures' resulting data relate to and inform each other and thus further readability literature.

According to the results of the cline procedure, the process essay was reported to be the easiest, followed by argumentation, contrast, narrative, and description. Although the purpose of this study was not to provide a taxonomy, these results offer an important contribution to rhetorical organization taxonomy literature (Carrell, 1984b; Fooh, 1989; Freedle \& Kostin, 1991, 1993; Goh, 1990; Lei, 2010; Meyer \& Freedle, 1984; Sharp, 2002; Talbot et al., 1991; Yali \& Jiliang, 2007; Zhang, 2008), as previous studies have not sufficiently reported the reading levels of texts and participants. This study also furthers the discussion as the essays (and accompanying analysis) are identified with terms commonly used in modern composition texts (i.e., process, description, narrative, cause/effect, comparison/contrast, and argumentation/persuasion), thus facilitating interpretation and replication.

Regarding what contributes to readers' perceptions of difficulty, the results indicated that rhetorical organization impacts readability as (a) a primary (isolated feature) and (b) a conjoined feature (consisting of two or more associated entities where the second affects the first, i.e., a feature influences the impact of rhetorical organization or rhetorical organization impacts another feature). As a primary feature driven by readers' formal schemata, the findings extend the literature that argues that readers' perceptions of rhetorical organizational difficulty are related to readers' formal schemata (Calfee \& Curley,1984; Carrell, 1987; Flick \& Anderson, 1980; Selinker et al., 1976).

As a conjoined feature, the results also extend readability literature; that is, in the areas of vocabulary, background knowledge, and titles. With regard to vocabulary, the results support the argument that readers' understanding of rhetorical structure is influenced by their ability to comprehend the associated vocabulary (Davis,1944; Freedle \& Kostin,1991, 1993; Hirsch \& Nation, 1992). The findings also extend the literature on the confluence of titles and organizational structure, in that readers' ability to understand organizational structure is assisted by titles (Bock, 1980; Schwartz \& Flammer, 1981). The work also makes a unique contribution to readability literature by identifying a conjoined relationship between rhetorical organization and background knowledge (content schemata).

These findings corroborate and further the literature that argues that considerations of readability need to go beyond the measurements of only two features (semantic and syntactic) and take into consideration the heterogeneous mix of features that contribute to a good fit between text and reader (Baker, 2020; Goodman;1967; Koda, 2005).

This study makes a significant contribution to readability literature as it demonstrates how rhetorical organization contributes to ELL apprenticing writers' perceptions of difficulty when reading essays excerpted from rhetorics. Overall, the results can be interpreted to mean that rhetorical organization is a contributory feature, but one that is slightly less influential than the two features utilized by quantitative readability formulae (i.e., semantic and syntactic). This result extends the work of Chall and Dale (1995) and others (Fry, 2002; Gunning, 2003; Lexile, 2010; Meyer, 2003; Weaver, 2000; Zakaluk \& Samuels, 1988), which posit that while quantitative readability formulae are worthy initial starting blocks for readability assessments, other features that formulae do not measure (e.g., rhetorical organization) need to be considered sequentially, first by employing quantitative readability formulae and then qualitatively considering the influence of subjective features that are not measured by readability formulae.

\section{Implications}

This study provides several unique contributions to the literature. First, it advances readability literature with regard to rhetorical organization and ELL apprenticing writers' perceptions of text difficulty when reading exemplars excerpted from rhetorics. The findings also provide practical implications in the area of text 
selection for those engaged with writing education (e.g., instructors, writing center staff, and the research community as a whole), as the teaching of writing, writing centers, and writing center self-access libraries are becoming standard in L2 university contexts (Baker, 2018; Devanadera, 2018; Paiz, 2017). Specifically, that rhetorical organization's contribution to the readability mix as a primary feature, and in conjunction with its conjoining features, needs to be considered during the hybrid text selection process. Similarly, the findings provide practical implications for the publishing community, as readability is a crucial consideration when selecting exemplars for inclusion in the 200-plus rhetorics published annually (Bloom, 1999).

\section{Limitations and Suggestions for Future Research}

While the study makes several unique contributions, the resulting data raise questions that may guide future explorations. First, in keeping with qualitative theory, the informants were purposively selected to better understand the problem (Creswell \& Creswell, 2018) and adhered to Kvale (1996) and others' (Creswell, 2013; Francis et al., 2010; Kuzel, 1992) purposive sample recommendations, namely $15 \pm 10$, a size common in interview studies. However, investigations employing more extensive samples may provide alternative results. A second related limitation is that although the study's results may be generalizable beyond the study's context, replicability and generalizability theory are important concerns (Strube, 2000). In other words, given that replicationis key to scientific research (National Academies of Sciences, 2019), additional studies should be undertaken, as different populations in other contexts may have alternate experiences. Third, although this study has furthered readability literature, rhetorical organization is still a much-understudied area, especially the readability of exemplars found in rhetorics in other contexts. Moreover, further discussions of other features that contribute to the readability of essays found in rhetorics still need to take place. It is, therefore, hoped that this paper will provide a foundation for future investigations. In keeping with this, this empirical study provides detailed literature review, methodology, and results sections to help mark a starting point for replication studies and further discussions of how rhetorical organization and other features impact the readability of essay exemplars.

\section{Acknowledgments}

I would like to thank the Head Editor Elena V. Tikhonova and editors and reviewers of the Journal of Language and Education for their suggestions and guidance, Saqib Sohail for his contributions as a statistical analyst, Daniel Steve Villarreal for his editing suggestions, and all those who participated in the study.

\section{Funding}

This paper was funded by Ton Duc Thang University (TDTU), Ho Chi Minh City, Vietnam.

\section{References}

Abe, M. (2009). Noticing in comparing own essay with model essay: An exploratory study of Japanese L2 writers. The bulletin of the Kanto-koshin-etsu English Language Education Society, 23, 71-82. https://doi.org/10.20806/ katejo.23.0_71

Armbruster, B, B. (2016). Matching readers and texts: The continuing quest. In Lapp, D., Flood, F., \& Farnan, N. (Eds), Content area reading and learning: Instructional strategies (pp. 47-64). Routledge. https://doi. org/10.46451/ijts.2020.06.08

Baker, J. R. (2020). A checklist for use with the Lexile Readability Formula when choosing materials for the writing center self-access library. Asian ESP Journal, 16(61), 9-68.

Baker, J. R. (2019). Writing about the writing center in the Asian context: Exploring the mis/match between the reading levels of self-access materials and the students who visit the center. The Asian ESP Journal, 15(3), 256-285. https://www.asian-esp-journal.com/volume-15-issue-3-december-2019/

Baker, J. R., \& Chung, Y. S. (2018). Writing about the writing center: Exploring what factors motivate writing center usage outside the north American context. Asian ESP Journal, 14(7.1), 7-56.

Bengeleil, N. F., \& Paribakht, T.S. (2004). L2 reading proficiency and lexical inferencing by university EFL learners. 
The Canadian Modern Language Review/La revue canadienne des langues vivantes, 61(2), 225-249. https://doi. org/10.3138/cmlr.61.2.225

Bereiter, C. (1978). Discourse type, schema, and strategy: A view from the standpoint of traditional design. Paper presented at the AERA, Toronto.

Bloom, L. (1999). The essay canon. College English, 61(4), 401-430. https://doi.org/10.1016/S8755-4615(89)800167

Bock, M. (1980). Some effects of titles on building and recalling text structures. Discourse Processes, 3(4), 301311. https://doi.org/1080/01638538009544494

Calfee, R. C., \& Curley, R. (1984). Structure of prose in the content areas. In J. Flood (Ed.), Understanding reading comprehension (pp. 161-180). International Reading Association.

Carrell, P. L. (1983a). Some issues in studying the role of schemata, or background knowledge, in second language comprehension. Reading in a Foreign Language, 1(2), 81-92.

Carrell, P. L. (1983b). Three components of background knowledge in reading comprehension. Language Learning, 33(2), 183-203. https://doi.org/10.1111/j.1467-1770.1983.tb00534.x

Carrell, P. L. (1984a). The effects of rhetorical organization on ESL readers. TESOL Quarterly, 18(3), 441469. https://doi.org/10.2307/3586714

Carrell, P. L. (1984b). Evidence of a formal schema in second language comprehension. Language Learning, 34(2), 87-108. https://doi.org/10.1111/j.14671770.1984.tb01005.x

Carrell, P. L. (1987). Content and formal schemata in ESL reading. TESOL Quarterly, 21(3), 461-481. https://doi. org/10.2307/3586498

Chall, J. S., Bissex, G. L., Conrad, S. S., \& Harris-Sharples, S. (1996). Qualitative assessment of text difficulty. Brookline Books.

Chall, J.S., \& Dale, E. (1995). Readability revisited: The new Dale-Chall readability formula. Brookline Books.

Chromik, M. (2002). Proofreading, its value, and its place in the writing center (EJ929331). ERIC.

Creswell, J. W. (2013). Research design: Qualitative, quantitative, and mixed methods approaches (4th ed.). Sage.

Creswell, J. W., \& Creswell, J. D. (2018). Research design: Qualitative, quantitative, and mixed methods approaches. Sage.

Dale, E., \& Chall, J. S. (1949). The concept of readability. Elementary English, 26, 19-26. https://doi. org/10.1111/j.1467-9345.1968.tb00749.x

Dalfonos, D. (2003). Grammy rewards. In T. Cooley (Ed.), The Norton sampler: Short essays for composition (pp. 206-208). Norton \& Company.

Davis, F. B. (1944). Fundamental factors of comprehension in reading. Psychometrika, 9(3), 185-197. https://doi. org/10.1007/bf02288722

Devanadera, A. C. (2018) Assessing Vietnamese EFL students' writing in the light of world Englishes. The Journal of English as and International Language, 13(2), 88-105.

Dochy, F., Segers, M., \& Buehl, M. M. (1999). The relation between assessment practices and outcomes of studies: The case of research on prior knowledge. Review of Educational Research, 69(2), 145-186. https://doi. org/10.3102/00346543069002145

Dubay, W. (2007a). Unlocking language: The classic readability studies. Impact Information.

Dubay, W. (2007b). Smart language: Readers, readability, and the grading of the text. Impact Information.

Dubin, F., \& Olshtain, E. (1993). Predicting word meanings from contextual clues: Evidence from L1 readers. In T. Huckin, M. Haynes \& J. Coady (Eds.), Second language reading and vocabulary learning (pp. 181-202). Abex.

Erlandson, D. A., Harris, E. L., Skipper, B. L., \& Allen, S. D. (1993). Doing naturalistic inquiry: A guide to methods. Sage.

Ferris, D., \& Hedgcock J. (2005). Teaching ESL composition: Purpose, process, and practice. Lawrence Erlbaum Associates.

Flick, W. C, \& Anderson, J. I. (1980). Rhetorical difficulty in scientific English: A study in reading comprehension. TESOL Quarterly, 14(3), 345-351. https://doi.org/10.2307/3586599

Fooh, R. W. K. (1989). A reading experiment with L2 readers of English in Hong Kong: Effects of the rhetorical structure of expository texts on reading comprehension. Hong Kong papers in linguistics and language teaching, 12, 49-62. ERIC.

Francis, J. J., Johnston, M., Robertson, C., Glidewell, L., Entwistle, V., Eccles, M. P., \& Grimshaw, J. M. (2010). What is an adequate sample size? Operationalizing data saturation for theory-based interview studies. Psychology and health, 25(10), 1229-1245. https://doi.org/10.1080/08870440903194015

Freedle, R., \& Kostin, I. (1991). The prediction of SAT reading comprehension item difficulty for expository prose passages. ERIC. 
Freedle, R., \& Kostin, I. (1993). The prediction of TOEFL reading comprehension item difficulty for expository prose passages for three item types: Main Idea, inference, and supporting idea items. ERIC.

Fry, E. (2002). Readability versus leveling: Both of these procedures can help teachers select books for readers at different stages. The Reading Teacher, 56(3), 286-292.

Gilliand, G. (1972). Readability. Hodder and Stoughton.

Goh, S. T. (1990). The effects of rhetorical organization on expository prose on ESL readers in Singapore. RELC Journal, 21(2), 1-11. https://doi.org/10.1177/003368829002100201

Goodman, K. S. (1967). Reading: A psycholinguistic guessing game. Journal of the Reading Specialist, 6(4), 126135. https://doi.org/10.1080/19388076709556976

Grabe, W., \& Zhang, C. (2016). Reading-writing relationships in first and second language academic literacy development. Language Teaching, 49(3), 339-355. https://doi.org/10.1017/S0261444816000082

Grimes, J. E. (1975). The thread of discourse. ERIC

Gunning, T. G. (2003). The role of readability in today's classrooms. Topics in Language Disorders, 23(3), 175189. https://doi.org/10.1097/00011363-200307000-00005

Harris, S. (2001). Freedom and security. In G. Levin (Ed.), Prose models (4th ed., pp. 389-392). Wadsworth.

Harrison, C. (1980). Readability in the classroom. Cambridge University Press.

Hirsch, D., \& Nation, P. (1992). What vocabulary size is needed to read unsimplified texts for pleasure? Reading in a Foreign Language, 8(2), 689-696.

Hughes, L. (2007). Salvation. In S. V. Buscemi, \& C. Smith (Eds.), 75 readings plus (pp. 10-14). McGraw-Hill.

Hyland, K. (2007). Genre pedagogy: Language, literacy and L2 writing instruction. Journal of second language writing, 16(3), 148-164. https://doi.org/10.1016/j.jslw.2007.07.005

Johns, A. M. (2003). Genre and ESL/EFL composition instruction. In B. Kroll (Ed.) Exploring the dynamics of second language writing (pp. 195-217). Cambridge University Press. https://doi.org/10.1017/CBO9781139524810.014

Koda, K. (2005). Insights into second language reading: A cross-linguistic approach. Cambridge University Press.

Kintsch, W., \& Miller, J. R. (1981). Readability: A view from cognitive psychology. In J. Flood (Ed.), Understanding reading comprehension (pp. 220-232). International Reading Association.

Kintsch, W., \& Vipond, D. (1979). Reading comprehension and readability in educational practice and psychological theory. In L. G. Nilsson (Ed.), Perspectives on memory research (pp. 329-366). Lawrence Erlbaum Associates.

Klare, G. (1963). The measurement of readability. Iowa State Press.

Klare, G. (1984). Readability. In P. D. Pearson (Ed.), Handbook of reading research (vol. 1, pp. 681-744). Longman.

Kuzel, A. 1992. Sampling in qualitative inquiry. In B. Crabtree, \& W. Miller (Eds). Doing qualitative research (pp. 31-44). Sage.

Kvale, S. (1996). Interviews: An introduction to qualitative research interviewing. Sage.

Liao, M. T., \& Chen, C. H. (2009). Rhetorical strategies in Chinese and English: A comparison of L1 composition textbooks. Foreign Language Annals, 42(4), 695-720. https://doi.org/10.1111/j.1944-9720.2009.01050.x

Lei, J. (2010). An investigation of the effects of discourse types on Taiwanese college students reading strategy use [Unpublished doctoral dissertation]. Indiana University of Pennsylvania.

Lexile. (2010). Lexile Professional Anaylzer. http://lexile.com/analyzer

Lively, B., \& Pressey, S. (1923). A method for measuring the vocabulary burden of textbooks. Educational Administration and Supervision, 9, 389-398.

Lorge, I. (1944). Word lists as background for communication. Teachers College Record, 45(8), 543-552. http:// www.tcrecord.org

McDonald, C. P. (2003). A view from the bridge. In T. Cooley (Ed.), The Norton sampler: Short essays for composition (pp. 37-41). Norton \& Company.

Merriam, S. B. (1991). Case study research in education: A qualitative approach. Jossey-Bass.

Mesmer, H. (2008). Tools for matching readers to texts. Guilford Press.

Meyer, B. J. F. (1975). The organization of prose and its effects on memory. North-Holland.

Meyer, B. J. F. (2003). Text coherence and readability. Topics in Language Disorders, 23(3), 204-224. https://doi.or $\mathrm{g} / 10.1097 / 0001136320030700000007$

Meyer, B. J. F., \& Freedle, R. O. (1984). Effects of discourse type on recall. American Educational Research Journal, 21(1), 121-143. https://doi.org/10.2307/1162357

National Academies of Sciences, Engineering, and Medicine. (2019) Reproducibility and replicability in science. National Academies Press.

Nunan, D. (1996). Towards autonomous learning: Some theoretical, empirical, and practical issues. In R. Pemberton, E. S. L., Li, W. W. F. Or, \& H. D. Pierson (Eds.), Taking control: Autonomy in language learning (pp. 13-26). Hong Kong University Press. 
Ojemann, R. H. (1932). The reading ability of parents and factors associated with reading difficulty of parent education materials. Presented at the meeting of Iowa Academy of Science. https://core.ac.uk/download/ pdf/222999801.pdf

Paiz, J. M. (2017). Uses of and attitudes towards OWLs as L2 writing support tools. Asian EFL Journal, 19(1), 5680.

Paribakht, T. S., \& Wesche, M. (1999). Reading and «incidental» L2 vocabulary acquisition: An introspective study of lexical inferencing. Studies in Second Language Acquisition, 21(2), 195-224.

Pearson, P. D., Kamil, M. L., Mosenthal, P. B., \& Barr, R. (Eds.). (2016). Handbook of reading research. Routledge.

Qi, D. S., \& Lapkin, S. (2001). Exploring the role of noticing in a three-stage second language writing task. Journal of second language writing, 10(4), 277-303. https://doi.org/10.1016/S1060-3743(01)00046-7

Schirmer, A., \& Lockman, B. R. (2001). How do I find a book to read? Middle and high school students use a rubric for self-selecting material for independent reading. Teaching Exceptional Children, 34(1), 36-42. https://doi. org/10.1177/004005990103400105

Schwartz, M., \& Flammer, A. (1981). Text structure and title-effects on comprehension and recall. Journal of Verbal Learning and Verbal Behavior, 20(3), 61-66. https://doi.org/10.1016/S00225371(81)90301-7

Selinker, L., Trimble, R. M., \& Trimble, L. (1976). Presuppositional rhetorical information in EST discourse. TESOL Quarterly, 10(3), 281-290. https://doi.org/10.2307/3585704

Sharp, A. (2002). Chinese L1 schoolchildren reading in English: The effects of rhetorical patterns. Reading in a Foreign Language, 14(2), 1-22.

Spiro, R. J., \& Taylor, B. M. (1980). On investigating children's transition from narrative to expository discourse: The multidimensional nature of psychological text classification. ERIC. https://eric.ed.gov/?id=ED199666

Strube, M. J. (2000). Reliability and generalizability theory. In L. G. Grimm, \& P. R. Yarnold (Eds.), Reading and understanding MORE multivariate statistics (p. 23-66). American Psychological Association.

Talbot, D., Ng, P., \& Allan, A. (1991). Hong Kong students reading expository prose: Replication of the effects of rhetorical organization on ESL readers by Patricia Carrell. Working Papers of the Department of English, City Polytechnic of Hong Kong, 3(1), 52-65. https://digitalrepository.lib.hku.hk

Traig, J. (2008). A guide to proper hand-washing technique. In M. L. Conlin (Ed.), Patterns plus: A short prose reader with argumentation (9th ed., pp. 176-178). Houghton Mifflin.

Weaver, B. M. (2000). Leveling books K-6: Matching readers to text. International Reading Association.

Yali, S., \& Jiliang, C. (2007). Effects of text type and test type on L2 reading comprehension test performance. CELEA Journal, 30(2), 16-14.

Zakaluk, B. L., \& Samuels, S. J. (1988). Toward a new approach to predicting text comprehensibility. In B. L. Zakaluk, \& S. J. Samuels (Eds.), Readability: Its past, present, and future (pp. 121-140). International Reading Association.

Zhang, X. (2008). The effects of formal schema on reading comprehension - An experiment with Chinese EFL readers. Computational Linguistics and Chinese Language Processing, 13(2), 197-214. 